\title{
AN IMPLICIT ITERATES FOR NON-LIPSCHITZIAN ASYMPTOTICALLY QUASI-NONEXPANSIVE TYPE MAPPINGS IN CAT(0) SPACES
}

\author{
G. S. SAluja
}

\begin{abstract}
The purpose of this paper is to establish strong convergence of an implicit iteration process to a common fixed point for a finite family of asymptotically quasi-nonexpansive type mappings in $\mathbf{C A T}(\mathbf{0})$ spaces. Our results improve and extend the corresponding results of Fukhar-uddin et al. [15] and some others from the current literature.
\end{abstract}

\section{Introduction}

A metric space $X$ is a CAT(0) space if it is geodesically connected and if every geodesic triangle in $X$ is at least as "thin" as its comparison triangle in the Euclidean plane. The precise definition is given below. It is well known that any complete, simply connected Riemannian manifold having nonpositive sectional curvature is a $\operatorname{CAT}(0)$ space. Other examples include Pre-Hilbert spaces (see $[3]), \mathbb{R}$-trees (see [27]), Euclidean buildings (see [4]), the complex Hilbert ball with a hyperbolic metric (see [16]), and many others. For a thorough discussion of these spaces and of the fundamental role they play in geometry, we refer the reader to Bridson and Haefliger [3].

Fixed point theory in CAT(0) spaces was first studied by Kirk (see [25, $26]$ ). He showed that every nonexpansive (single-valued) mapping defined on a bounded closed convex subset of a complete CAT(0) space always has a fixed point. Since then the fixed point theory for single-valued and multi-valued mappings in $\mathrm{CAT}(0)$ spaces has been rapidly developed and many papers have appeared (see, e.g., [1], [6]-[9], [18], [21], [24], [29]-[31], [33] and references therein). It is worth mentioning that fixed point theorems in $\operatorname{CAT}(0)$ spaces (specially in $\mathbb{R}$-trees) can be applied to graph theory, biology and computer science (see,e.g., $[2,10,26,28,32]$ ).

Let $(X, d)$ be a metric space. A geodesic path joining $x \in X$ to $y \in X$ (or, more briefly, a geodesic from $x$ to $y$ ) is a map $c$ from a closed interval $[0, l] \subset \mathbb{R}$ to $X$ such that $c(0)=x, c(l)=y$, and let $d\left(c(t), c\left(t^{\prime}\right)\right)=\left|t-t^{\prime}\right|$ for

Received August 28, 2011; Accepted November 4, 2011.

2000 Mathematics Subject Classification. 54H25, 54E40.

Key words and phrases. Asymptotically quasi-nonexpansive type mapping, implicit iteration process, common fixed point, strong convergence, $\mathrm{CAT}(0)$ space. 
all $t, t^{\prime} \in[0, l]$. In particular, $c$ is an isometry, and $d(x, y)=l$. The image $\alpha$ of $c$ is called a geodesic (or metric) segment joining $x$ and $y$. We say $X$ is (i) a geodesic space if any two points of $X$ are joined by a geodesic and (ii) uniquely geodesic if there is exactly one geodesic joining $x$ and $y$ for each $x, y \in X$, which we will denoted by $[x, y]$, called the segment joining $x$ to $y$.

A geodesic triangle $\triangle\left(x_{1}, x_{2}, x_{3}\right)$ in a geodesic metric space $(X, d)$ consists of three points in $X$ (the vertices of $\triangle$ ) and a geodesic segment between each pair of vertices (the edges of $\triangle$ ). A comparison triangle for geodesic triangle $\triangle\left(x_{1}, x_{2}, x_{3}\right)$ in $(X, d)$ is a triangle $\bar{\triangle}\left(x_{1}, x_{2}, x_{3}\right):=\triangle\left(\overline{x_{1}}, \overline{x_{2}}, \overline{x_{3}}\right)$ in $\mathbb{R}^{2}$ such that $d_{\mathbb{R}^{2}}\left(\overline{x_{i}}, \overline{x_{j}}\right)=d\left(x_{i}, x_{j}\right)$ for $i, j \in\{1,2,3\}$. Such a triangle always exists (see $[3])$.

A geodesic metric space is said to be a $C A T(0)$ space if all geodesic triangles of appropriate size satisfy the following $C A T(0)$ comparison axiom.

Let $\triangle$ be a geodesic triangle in $X$ and let $\triangle \subset \mathbb{R}^{2}$ be a comparison triangle for $\triangle$. Then $\triangle$ is said to satisfy the $C A T(0)$ inequality if for all $x, y \in \triangle$ and all comparison points $\bar{x}, \bar{y} \in \bar{\triangle}$,

$$
d(x, y) \leq d(\bar{x}, \bar{y})
$$

Complete $C A T(0)$ spaces are often called Hadamard spaces (see [20]). If $x, y_{1}, y_{2}$ are points of a $C A T(0)$ space and $y_{0}$ is the mid point of the segment $\left[y_{1}, y_{2}\right]$ which we will denote by $\left(y_{1} \oplus y_{2}\right) / 2$, then the $C A T(0)$ inequality implies

$$
d^{2}\left(x, \frac{y_{1} \oplus y_{2}}{2}\right) \leq \frac{1}{2} d^{2}\left(x, y_{1}\right)+\frac{1}{2} d^{2}\left(x, y_{2}\right)-\frac{1}{4} d^{2}\left(y_{1}, y_{2}\right)
$$

The inequality $(2)$ is the $(C N)$ inequality of Bruhat and Titz [5]. The above inequality has been extended in [8] as

$$
\begin{aligned}
d^{2}(z, \alpha x \oplus(1-\alpha) y) \leq & \alpha d^{2}(z, x)+(1-\alpha) d^{2}(z, y) \\
& -\alpha(1-\alpha) d^{2}(x, y)
\end{aligned}
$$

for any $\alpha \in[0,1]$ and $x, y, z \in X$.

Let us recall that a geodesic metric space is a $C A T(0)$ space if and only if it satisfies the $(C N)$ inequality (see [3, page 163]). Moreover, if $X$ is a $C A T(0)$ metric space and $x, y \in X$, then for any $\alpha \in[0,1]$, there exists a unique point $\alpha x \oplus(1-\alpha) y \in[x, y]$ such that

$$
d(z, \alpha x \oplus(1-\alpha) y) \leq \alpha d(z, x)+(1-\alpha) d(z, y)
$$

for any $z \in X$ and $[x, y]=\{\alpha x \oplus(1-\alpha) y: \alpha \in[0,1]\}$.

A subset $C$ of a $C A T(0)$ space $X$ is convex if for any $x, y \in C$, we have $[x, y] \subset C$.

Let $T$ be a self map on a nonempty subset $C$ of $X$. Denote the set of fixed points of $T$ by $F(T)=\{x \in C: T(x)=x\}$. We say that $T$ is: 
(1) asymptotically nonexpansive if there exists a sequence $\left\{k_{n}\right\} \subset[1, \infty)$ with $\lim _{n \rightarrow \infty} k_{n}=1$ such that

$$
d\left(T^{n} x, T^{n} y\right) \leq k_{n} d(x, y)
$$

for all $x, y \in C$ and $n \geq 1$.

(2) asymptotically quasi-nonexpansive if $F(T) \neq \emptyset$ and there exists a sequence $\left\{k_{n}\right\} \subset[1, \infty)$ with $\lim _{n \rightarrow \infty} k_{n}=1$ such that

$$
d\left(T^{n} x, p\right) \leq k_{n} d(x, p)
$$

for all $x \in C, p \in F(T)$ and $n \geq 1$.

(3) asymptotically quasi-nonexpansive type if $F(T) \neq \emptyset$ and

$$
\limsup _{n \rightarrow \infty}\left\{\sup _{x \in C, p \in F(T)}\left(d\left(T^{n} x, p\right)-d(x, p)\right)\right\} \leq 0
$$

(4) uniformly $L$-Lipschitzian if there exists a constant $L>0$ such that

$$
d\left(T^{n} x, T^{n} y\right) \leq L d(x, y)
$$

for all $x, y \in C$ and $n \geq 1$.

(5) semi-compact if for any bounded sequence $\left\{x_{n}\right\}$ in $C$ with $d\left(x_{n}, T x_{n}\right) \rightarrow$ 0 as $n \rightarrow \infty$, there is a convergent subsequence of $\left\{x_{n}\right\}$.

Denote the indexing set $\{1,2, \ldots, N\}$ by $I$. Let $\left\{T_{i}: i \in I\right\}$ be the set of $N$ self mappings of $C$. Throughout the paper, it is supposed that $F=$ $\bigcap_{i=1}^{N} F\left(T_{i}\right) \neq \emptyset$. We say condition $(\mathrm{A})$ [15] is satisfied if there exists a nondecreasing function $f:[0, \infty) \rightarrow[0, \infty)$ with $f(0)=0, f(r)>0$ for all $r \in(0, \infty)$ and at least one $T \in\left\{T_{i}: i \in I\right\}$ such that $d(x, T x) \geq f(d(x, F))$ for all $x \in C$ where $d(x, F)=\inf \{d(x, p): p \in F\}$.

Recently, number of papers have appeared on the iterative approximation of fixed points of asymptotically nonexpansive (asymptotically quasi-nonexpansive) mappings through Mann, Ishikawa and implicit iterates in uniformly convex Banach spaces, convex metric spaces and CAT(0) spaces (see, e.g., [11]-[14], [17], [19], [21]-[23], [34], [36]).

Very recently, Fukhar-ud-din et al. [15] generalized the Sun's [34] implicit algorithm in CAT(0) space by using the concept of convexity in CAT(0) space. The generalized implicit algorithm is as follows:

$$
x_{0} \in C
$$




$$
\begin{array}{rll}
x_{1} & = & \alpha_{1} x_{0} \oplus\left(1-\alpha_{1}\right) T_{1} x_{1}, \\
x_{2} & = & \alpha_{2} x_{1} \oplus\left(1-\alpha_{2}\right) T_{2} x_{2}, \\
\vdots & & \\
x_{N} & = & \alpha_{N} x_{N-1} \oplus\left(1-\alpha_{N}\right) T_{N} x_{N}, \\
x_{N+1} & = & \alpha_{N+1} x_{N} \oplus\left(1-\alpha_{N+1}\right) T_{1}^{2} x_{N+1}, \\
\vdots & & \\
x_{2 N} & =\alpha_{2 N} x_{2 N-1} \oplus\left(1-\alpha_{2 N}\right) T_{N}^{2} x_{2 N}, \\
x_{2 N+1} & =\alpha_{2 N+1} x_{2 N} \oplus\left(1-\alpha_{2 N+1}\right) T_{1}^{3} x_{2 N+1},
\end{array}
$$

where $0 \leq \alpha_{n} \leq 1$

Starting from arbitrary $x_{0} \in C$, the above process in the compact form can be written as

$$
x_{n}=\alpha_{n} x_{n-1} \oplus\left(1-\alpha_{n}\right) T_{i(n)}^{k(n)} x_{n}, \quad n \geq 1,
$$

where $n=(k-1) N+i, i=i(n) \in I$ and $k=k(n) \geq 1$ is a positive integer such that $k(n) \rightarrow \infty$ as $n \rightarrow \infty$. They have proved some strong convergence theorems using implicit iteration scheme (10) for a finite family of generalized asymptotically quasi-nonexpansive mappings in $\mathrm{CAT}(0)$ space and also gave the necessary and sufficient condition to converge to common fixed point for said mappings in $\operatorname{CAT}(0)$ space.

In a normed space, iteration scheme (10) can be written as

$$
x_{n}=\alpha_{n} x_{n-1}+\left(1-\alpha_{n}\right) T_{i(n)}^{k(n)} x_{n}, \quad n \geq 1,
$$

where $n=(k-1) N+i, i=i(n) \in I$ and $k=k(n) \geq 1$ is a positive integer such that $k(n) \rightarrow \infty$ as $n \rightarrow \infty$.

The iteration scheme (10) - (11) exist as follows.

Let $X$ be a $\mathrm{CAT}(0)$ space. Then, the following inequality holds:

$$
d(\lambda x \oplus(1-\lambda) z, \lambda y \oplus(1-\lambda) w) \leq \lambda d(x, y)+(1-\lambda) d(z, w),
$$

for all $x, y, z, w \in X$ (see [30]).

Denote the indexing set $\{1,2, \ldots, N\}$ by $I$. Let $\left\{T_{i}: i \in I\right\}$ be $N$ uniformly $L$-Lipschitzian asymptotically quasi-nonexpansive type self-mappings of $C$. We show that (12) exists. Let $x_{0} \in C$ and $x_{1}=\alpha_{1} x_{0} \oplus\left(1-\alpha_{1}\right) T_{1} x_{1}$. Define $W: C \rightarrow C$ by: $W x=\alpha_{1} x_{0} \oplus\left(1-\alpha_{1}\right) T_{1} x$ for all $x \in C$. The existence of $x_{1}$ is guaranteed if $W$ has a fixed point. For any $x, y \in C$, we have

$$
d(W x, W y) \leq\left(1-\alpha_{1}\right) d\left(T_{1} x, T_{1} y\right) \leq\left(1-\alpha_{1}\right) L d(x, y) .
$$

Now, $W$ is a contraction if $\left(1-\alpha_{1}\right) L<1$ or $L<1 /\left(1-\alpha_{1}\right)$. As $\alpha_{1} \in(0,1)$, therefore $W$ is a contraction even if $L>1$. By the Banach contraction principle, $W$ has a unique fixed point. Thus, the existence of $x_{1}$ is established. Similarly, 
we can establish the existence of $x_{2}, x_{3}, x_{4}, \ldots$ Thus, the implicit algorithm (10) is well defined. Similarly, we can prove that (11) exists.

The purpose of this paper is to study strong convergence of implicit iteration process (10) for the class of uniformly $L$-Lipschitzian and asymptotically quasinonexpansive type self mappings on a CAT(0) space. Our results extend the corresponding results of Fukhar-ud-din et al. [15] and many others.

We need the following useful lemma to prove our convergence results.

Lemma 1.1. (see [35]) Let $\left\{a_{n}\right\}$ and $\left\{b_{n}\right\}$ be sequences of nonnegative real numbers satisfying the inequality

$$
a_{n+1} \leq a_{n}+b_{n}, n \geq 1 .
$$

If $\sum_{n=1}^{\infty} b_{n}<\infty$, then $\lim _{n \rightarrow \infty} a_{n}$ exists. In particular, if $\left\{a_{n}\right\}$ has a subsequence converging to zero, then $\lim _{n \rightarrow \infty} a_{n}=0$.

\section{Convergence in CAT(0) spaces}

We establish some convergence results for the iteration scheme (10) to a common fixed point of a finite family of uniformly $L$-Lipschitzian and asymptotically quasi-nonexpansive type self mappings in the framework of $\operatorname{CAT}(0)$ spaces.

Theorem 2.1. Let $(X, d)$ be a complete $C A T(0)$ space and let $C$ be a nonempty closed convex subset of $X$. Let Let $\left\{T_{i}: i \in I\right\}$ be $N$ uniformly L-Lipschitzian and asymptotically quasi-nonexpansive type self mappings of $C$. Suppose that $F$ is closed. Let $\left\{x_{n}\right\}$ be the implicit iteration process defined by (10). Put

$$
G_{i n}=\max \left\{0, \sup _{p \in F, n \geq 1}\left(d\left(T_{i}^{n} x_{n}, p\right)-d\left(x_{n}, p\right)\right): i \in I\right\},
$$

where $n=(k-1) N+i$ and $i=i(n) \in I$. Assume that $\sum_{n=1}^{\infty} G_{i n}<\infty$ and $\left\{\alpha_{n}\right\} \subset[s, 1-s]$ for some $s \in\left(0, \frac{1}{2}\right)$. Then the sequence $\left\{x_{n}\right\}$ converges strongly to a common fixed point $p$ of the mappings $\left\{T_{i}: i \in I\right\}$ if and only if

$$
\liminf _{n \rightarrow \infty} d\left(x_{n}, F\right)=0
$$

where $d(x, F)=\inf _{p \in F}\{d(x, p)\}$.

Proof. The necessity is obvious and so it is omitted. Now, we prove the sufficiency. For any $p \in F=\cap_{i=1}^{N} F\left(T_{i}\right)$ from (10) and (15), where $n \geq 1$, $n=(k-1) N+i$ and $i=i(n) \in I$, we have

$$
\begin{aligned}
d\left(x_{n}, p\right) & =d\left(\alpha_{n} x_{n-1} \oplus\left(1-\alpha_{n}\right) T_{i(n)}^{k(n)} x_{n}, p\right) \\
& \leq \alpha_{n} d\left(x_{n-1}, p\right)+\left(1-\alpha_{n}\right) d\left(T_{i(n)}^{k(n)} x_{n}, p\right) \\
& \leq \alpha_{n} d\left(x_{n-1}, p\right)+\left(1-\alpha_{n}\right)\left[d\left(x_{n}, p\right)+G_{i k(n)}\right] \\
& =\alpha_{n} d\left(x_{n-1}, p\right)+\left(1-\alpha_{n}\right) d\left(x_{n}, p\right)+\left(1-\alpha_{n}\right) G_{i k(n)} .
\end{aligned}
$$


Since $\alpha_{n} \in(s, 1-s)$, the above inequality gives that

$$
\begin{aligned}
d\left(x_{n}, p\right) & \leq d\left(x_{n-1}, p\right)+\left(\frac{1}{s}-1\right) G_{i k(n)} \\
& =d\left(x_{n-1}, p\right)+Q_{i k(n)},
\end{aligned}
$$

where $Q_{i k(n)}=\left(\frac{1}{s}-1\right) G_{i k(n)}$. Since $\sum_{k(n)=1}^{\infty} G_{i k(n)}<\infty$ for all $i \in I$, it follows that $\sum_{k(n)=1}^{\infty} Q_{i k(n)}<\infty$. Therefore, from Lemma 1.1, we know that $\lim _{n \rightarrow \infty} d\left(x_{n}, F\right)$ exists. Since by hypothesis $\liminf _{n \rightarrow \infty} d\left(x_{n}, F\right)=0$, so by Lemma 1.1, we have

$$
\lim _{n \rightarrow \infty} d\left(x_{n}, F\right)=0 .
$$

Next we prove that $\left\{x_{n}\right\}$ is a Cauchy sequence in $C$. It follows from (17) that for any $m \geq 1$, for all $n \geq n_{0}$ and for any $p \in F$, we have

$$
d\left(x_{n+m}, p\right) \leq d\left(x_{n}, p\right)+\sum_{i=1}^{N} \sum_{k(n)=1}^{\infty} Q_{i k(n)} .
$$

So, we have

$$
\begin{aligned}
d\left(x_{n+m}, x_{n}\right) & \leq d\left(x_{n+m}, p\right)+d\left(x_{n}, p\right) \\
& \leq d\left(x_{n}, p\right)+\sum_{i=1}^{N} \sum_{k(n)=1}^{\infty} Q_{i k(n)}+d\left(x_{n}, p\right) \\
& =2 d\left(x_{n}, p\right)+\sum_{i=1}^{N} \sum_{k(n)=1}^{\infty} Q_{i k(n)} .
\end{aligned}
$$

Then, we have

$$
d\left(x_{n+m}, x_{n}\right) \leq 2 d\left(x_{n}, F\right)+\sum_{i=1}^{N} \sum_{k(n)=1}^{\infty} Q_{i k(n)} .
$$

For any given $\varepsilon>0$, there exists a positive integer $n_{1} \geq n_{0}$ such that for any $n \geq n_{1}$,

$$
d\left(x_{n}, F\right)<\frac{\varepsilon}{4}
$$

and

$$
\sum_{i=1}^{N} \sum_{k(n)=1}^{\infty} Q_{i k(n)}<\frac{\varepsilon}{2}
$$

Thus, from (21)-(23) and $n \geq n_{1}$, we have

$$
d\left(x_{n+m}, x_{n}\right)<2 \cdot \frac{\varepsilon}{4}+\frac{\varepsilon}{2}=\varepsilon
$$


This implies that $\left\{x_{n}\right\}$ is a Cauchy sequence in $C$. Thus, the completeness of $X$ implies that $\left\{x_{n}\right\}$ must be convergent. Assume that $\lim _{n \rightarrow \infty} x_{n}=z$. Since $C$ is closed, therefore $z \in C$. Next, we show that $z \in F$. Now, the following two inequalities:

$$
\begin{aligned}
d(z, p) & \leq d\left(z, x_{n}\right)+d\left(x_{n}, p\right) \quad \forall p \in F, n \geq 1, \\
d\left(z, x_{n}\right) & \leq d(z, p)+d\left(x_{n}, p\right) \quad \forall p \in F, n \geq 1
\end{aligned}
$$

give that

$$
-d\left(z, x_{n}\right) \leq d(z, F)-d\left(x_{n}, F\right) \leq d\left(z, x_{n}\right), n \geq 1 .
$$

That is,

$$
\left|d(z, F)-d\left(x_{n}, F\right)\right| \leq d\left(z, x_{n}\right), n \geq 1 .
$$

As $\lim _{n \rightarrow \infty} x_{n}=z$ and $\lim _{n \rightarrow \infty} d\left(x_{n}, F\right)=0$, we conclude that $z \in F$.

Theorem 2.2. Let $(X, d)$ be a complete $C A T(0)$ space and let $C$ be a nonempty closed convex subset of $X$. Let $\left\{T_{i}: i \in I\right\}$ be $N$ uniformly L-Lipschitzian and asymptotically quasi-nonexpansive type self mappings of $C$. Suppose that $F$ is closed. Let $\left\{x_{n}\right\}$ be the implicit iteration process defined by (10). Put

$$
G_{i n}=\max \left\{0, \sup _{p \in F, n \geq 1}\left(d\left(T_{i}^{n} x_{n}, p\right)-d\left(x_{n}, p\right)\right): i \in I\right\},
$$

where $n=(k-1) N+i$ and $i=i(n) \in I$. Assume that $\sum_{n=1}^{\infty} G_{i n}<\infty$ and $\left\{\alpha_{n}\right\} \subset[s, 1-s]$ for some $s \in\left(0, \frac{1}{2}\right)$. Then the sequence $\left\{x_{n}\right\}$ converges strongly to a common fixed point $p$ of the mappings $\left\{T_{i}: i \in I\right\}$ if and only if there exists a subsequence $\left\{x_{n_{j}}\right\}$ of $\left\{x_{n}\right\}$ which converges to $p \in F$.

Proof. The proof of Theorem 2.2 follows from Lemma 1.1 and Theorem 2.1.

We prove a lemma which plays an important role in establishing strong convergence of the implicit iteration process with errors in a $C A T(0)$ space.

Lemma 2.3. Let $(X, d)$ be a complete $C A T(0)$ space and let $C$ be a nonempty closed convex subset of $X$. Let Let $\left\{T_{i}: i \in I\right\}$ be $N$ uniformly L-Lipschitzian and asymptotically quasi-nonexpansive type self mappings of $C$. Suppose that $F$ is closed. Let $\left\{x_{n}\right\}$ be the implicit iteration process defined by (10). Put

$$
G_{i n}=\max \left\{0, \sup _{p \in F, n \geq 1}\left(d\left(T_{i}^{n} x_{n}, p\right)-d\left(x_{n}, p\right)\right): i \in I\right\},
$$

where $n=(k-1) N+i$ and $i=i(n) \in I$. Assume that $\sum_{n=1}^{\infty} G_{i n}<\infty$ and $\left\{\alpha_{n}\right\} \subset[s, 1-s]$ for some $s \in\left(0, \frac{1}{2}\right)$. Then $\lim _{n \rightarrow \infty} d\left(x_{n}, T_{l} x_{n}\right)=0$ for all $l \in I$.

Proof. Note that $\left\{x_{n}\right\}$ is bounded as $\lim _{n \rightarrow \infty} d\left(x_{n}, p\right)$ exists (proved in Theorem 2.1). So, there exists $R>0$ and $x_{0} \in X$ such that $x_{n} \in B_{R}\left(x_{0}\right)=\{x$ : $\left.d\left(x, x_{0}\right)<R\right\}$ for all $n \geq 1$. Let $\sigma_{n}=d\left(x_{n-1}, T_{i(n)}^{k(n)}\right)$.

We claim that $\lim _{n \rightarrow \infty} \sigma_{n}=0$. 
For any $p \in F$, using (3) and (10), we get

$$
\begin{aligned}
d^{2}\left(x_{n}, p\right)= & d^{2}\left(\alpha_{n} x_{n-1} \oplus\left(1-\alpha_{n}\right) T_{i(n)}^{k(n)} x_{n}, p\right) \\
\leq & \alpha_{n} d^{2}\left(x_{n-1}, p\right)+\left(1-\alpha_{n}\right) d^{2}\left(T_{i(n)}^{k(n)} x_{n}, p\right) \\
& -\alpha_{n}\left(1-\alpha_{n}\right) d^{2}\left(T_{i(n)}^{k(n)} x_{n}, x_{n-1}\right) \\
\leq & \alpha_{n} d^{2}\left(x_{n-1}, p\right)+\left(1-\alpha_{n}\right)\left[d\left(x_{n}, p\right)+G_{i k(n)}\right]^{2} \\
& -\alpha_{n}\left(1-\alpha_{n}\right) d^{2}\left(T_{i(n)}^{k(n)} x_{n}, x_{n-1}\right) \\
\leq & \alpha_{n} d^{2}\left(x_{n-1}, p\right)+\left(1-\alpha_{n}\right)\left[d^{2}\left(x_{n}, p\right)+\delta_{i k(n)}\right] \\
& -\alpha_{n}\left(1-\alpha_{n}\right) d^{2}\left(T_{i(n)}^{k(n)} x_{n}, x_{n-1}\right)
\end{aligned}
$$

where $\delta_{i k(n)}=G_{i k(n)}^{2}+2 G_{i k(n)} d\left(x_{n}, p\right)$. Since $\sum_{k(n)=1}^{\infty} G_{i k(n)}<\infty$, it follows that $\sum_{k(n)=1}^{\infty} \delta_{i k(n)}<\infty$.

Since $s \leq \alpha_{n} \leq(1-s)$, from (27), we obtain

$$
\begin{aligned}
s^{2} \sigma_{n}^{2} \leq & \alpha_{n} d^{2}\left(x_{n-1}, p\right)-d^{2}\left(x_{n}, p\right)+\left(1-\alpha_{n}\right) d^{2}\left(x_{n}, p\right) \\
& +\left(1-\alpha_{n}\right) \delta_{i k(n)} \\
= & \alpha_{n} d^{2}\left(x_{n-1}, p\right)-\alpha_{n} d^{2}\left(x_{n}, p\right)+\left(1-\alpha_{n}\right) \delta_{i k(n)},
\end{aligned}
$$

further, using (17), we obtain

$$
\begin{aligned}
s^{2} \sigma_{n}^{2} \leq & \alpha_{n} d^{2}\left(x_{n-1}, p\right)-\alpha_{n}\left[d\left(x_{n-1}, p\right)+Q_{i k(n)}\right]^{2} \\
& +\left(1-\alpha_{n}\right) \delta_{i k(n)} \\
\leq & \alpha_{n} d^{2}\left(x_{n-1}, p\right)-\alpha_{n}\left[d^{2}\left(x_{n-1}, p\right)+\theta_{i k(n)}\right] \\
& +\left(1-\alpha_{n}\right) \delta_{i k(n)},
\end{aligned}
$$

where $\theta_{i k(n)}=Q_{i k(n)}^{2}+Q_{i k(n)} d\left(x_{n-1}, p\right)$. Since $\sum_{k(n)=1}^{\infty} Q_{i k(n)}<\infty$, it follows that $\sum_{k(n)=1}^{\infty} \theta_{i k(n)}<\infty$. The inequality (29) gives that

$$
\sigma_{n}^{2} \leq\left(\frac{1-s}{s^{2}}\right) \delta_{i k(n)}-\left(\frac{1}{s}\right) \theta_{i k(n)}
$$

For $m \geq 1$, we have that

$$
\sum_{n=1}^{m} \sigma_{n}^{2} \leq\left(\frac{1-s}{s^{2}}\right) \sum_{k(n)=1}^{m} \delta_{i k(n)}-\left(\frac{1}{s}\right) \sum_{k(n)=1}^{m} \theta_{i k(n)} .
$$

When $m \rightarrow \infty$, we have that $\sum_{n=1}^{\infty} \sigma_{n}^{2}<\infty$ as $\sum_{k(n)=1}^{\infty} \delta_{i k(n)}<\infty$ and $\sum_{k(n)=1}^{\infty} \theta_{i k(n)}<\infty$.

Hence,

$$
\lim _{n \rightarrow \infty} \sigma_{n}=0 .
$$


Further,

$$
\begin{aligned}
d\left(x_{n}, x_{n-1}\right) & \leq\left(1-\alpha_{n}\right) d\left(T_{i(n)}^{k(n)} x_{n}, x_{n-1}\right) \\
& =\left(1-\alpha_{n}\right) \sigma_{n} \leq(1-s) \sigma_{n}
\end{aligned}
$$

implies that $\lim _{n \rightarrow \infty} d\left(x_{n}, x_{n-1}\right)=0$.

For a fixed $j \in I$, we have $d\left(x_{n+j}, x_{n}\right) \leq d\left(x_{n+j}, x_{n+j-1}\right)+\cdots+d\left(x_{n}, x_{n-1}\right)$ and hence

$$
\lim _{n \rightarrow \infty} d\left(x_{n+j}, x_{n}\right)=0 \quad \forall j \in I .
$$

For $n>N, n=(n-N)(\bmod N)$. Also, $n=(k(n)-1) N+i(n)$. Hence, $n-N=((k(n)-1)-1) N+i(n)=k(n-N) N+i(n-N)$. That is, $k(n-N)=$ $k(n)-1$ and $i(n-N)=i(n)$.

Therefore, we have

$$
\begin{aligned}
d\left(x_{n-1}, T_{n} x_{n}\right) \leq & d\left(x_{n-1}, T_{i(n)}^{k(n)} x_{n}\right)+d\left(T_{i(n)}^{k(n)} x_{n}, T_{n} x_{n}\right) \\
\leq & \sigma_{n}+L d\left(T_{i(n)}^{k(n)-1} x_{n}, x_{n}\right) \\
\leq & \sigma_{n}+L^{2} d\left(x_{n}, x_{n-N}\right)+L d\left(T_{i(n-N)}^{k(n-N)} x_{n-N}, x_{(n-N)-1}\right) \\
& +L d\left(x_{(n-N)-1}, x_{n}\right) \\
= & \sigma_{n}+L^{2} d\left(x_{n}, x_{n-N}\right)+L \sigma_{n-N} \\
& +L d\left(x_{(n-N)-1}, x_{n}\right),
\end{aligned}
$$

using (32) and (34) in (35) yields that $\lim _{n \rightarrow \infty} d\left(x_{n-1}, T_{n} x_{n}\right)=0$.

Since,

$$
d\left(x_{n}, T_{n} x_{n}\right) \leq d\left(x_{n}, x_{n-1}\right)+d\left(x_{n-1}, T_{n} x_{n}\right)
$$

we have

$$
\lim _{n \rightarrow \infty} d\left(x_{n}, T_{n} x_{n}\right)=0 .
$$

Hence, for all $l \in I$, we have

$$
\begin{aligned}
d\left(x_{n}, T_{n+l} x_{n}\right) \leq & d\left(x_{n}, x_{n+l}\right)+d\left(x_{n+l}, T_{n+l} x_{n+l}\right) \\
& +d\left(T_{n+l} x_{n+l}, T_{n+l} x_{n}\right) \\
\leq & (1+L) d\left(x_{n}, x_{n+l}\right)+d\left(x_{n+l}, T_{n+l} x_{n+l}\right),
\end{aligned}
$$

using (34) and (37) in (38) implies that

$$
\lim _{n \rightarrow \infty} d\left(x_{n}, T_{n+l} x_{n}\right)=0 \quad \forall l \in I .
$$

Thus, $\lim _{n \rightarrow \infty} d\left(x_{n}, T_{l} x_{n}\right)=0$ for all $l \in I$.

Theorem 2.4. Let $(X, d)$ be a complete $C A T(0)$ space and let $C$ be a nonempty closed convex subset of $X$. Let Let $\left\{T_{i}: i \in I\right\}$ be $N$ uniformly L-Lipschitzian and asymptotically quasi-nonexpansive type self mappings of $C$. Suppose that 
$F$ is closed, and there exists one member $T$ in $\left\{T_{i}: i \in I\right\}$ which is either semicompact or satisfies condition $(A)$. Let $\left\{x_{n}\right\}$ be the implicit iteration process defined by (10). Put

$$
G_{i n}=\max \left\{0, \sup _{p \in F, n \geq 1}\left(d\left(T_{i}^{n} x_{n}, p\right)-d\left(x_{n}, p\right)\right): i \in I\right\},
$$

where $n=(k-1) N+i$ and $i=i(n) \in I$. Assume that $\sum_{n=1}^{\infty} G_{i n}<\infty$ and $\left\{\alpha_{n}\right\} \subset[s, 1-s]$ for some $s \in\left(0, \frac{1}{2}\right)$. Then $\left\{x_{n}\right\}$ converges strongly to a common fixed point of the mappings in $\left\{T_{i}: i \in I\right\}$.

Proof. Without loss of generality, we may assume that $T_{1}$ is semi-compact or satisfies condition $(A)$. If $T_{1}$ is semi-compact, then there exists a subsequence $\left\{x_{n_{j}}\right\}$ of $\left\{x_{n}\right\}$ such that $x_{n_{j}} \rightarrow p^{*} \in C$ as $j \rightarrow \infty$. Now, Lemma 2.3 guarantees that $\lim _{n \rightarrow \infty} d\left(x_{n_{j}}, T_{l} x_{n_{j}}\right)=0$ for all $l \in I$ and so $d\left(p^{*}, T_{l} p^{*}\right)=0$ for all $l \in I$. This implies that $p^{*} \in F$. Therefore, $\liminf _{n \rightarrow \infty} d\left(x_{n}, F\right)=0$. If $T_{1}$ satisfies condition $(A)$, then we also have $\liminf _{n \rightarrow \infty} d\left(x_{n}, F\right)=0$. Now, Theorem 2.1 guarantees that $\left\{x_{n}\right\}$ converges strongly to a point in $F$.

Remark 1. Our results extend the corresponding results of Fukhar-ud-din et al. [15] to the case of more general class of generalized asymptotically quasinonexpansive mappings considered in this paper.

\section{References}

[1] A. Akbar and M. Eslamian, Common fixed point results in CAT(0) spaces, Nonlinear Anal.: Theory, Method and Applications, Vol. 74 (2011), no. 5, 1835-1840.

[2] M. Bestvina, $\mathbb{R}$-trees in topology, geometry, and graph theory, in Handbook of geometric topology, 55-91, North-Holland, Amsterdam, The Netherlands, 2002.

[3] M. R. Bridson and A. Haefliger, Metric spaces of non-positive curvature, Vol. 319 of Grundlehren der Mathematischen Wissenschaften, Springer, Berlin, Germany, 1999.

[4] K. S. Brown, Buildings, Springer, New York, NY, USA, 1989.

[5] F. Bruhat and J. Tits, "Groups reductifs sur un corps local", Institut des Hautes Etudes Scientifiques. Publications Mathematiques, Vol. 41 (1972), 5-251.

[6] P. Chaoha and A. Phon-on, A note on fixed point sets in CAT(0) spaces, J. Math. Anal. Appl. 320 (2006), no. 2, 983-987.

[7] S. Dhompongsa, A. Kaewkho and B. Panyanak, Lim's theorems for multivalued mappings in CAT(0) spaces, J. Math. Anal. Appl. 312 (2005), no. 2, 478-487.

[8] S. Dhompongsa and B. Panyanak, On $\triangle$-convergence theorem in $C A T(0)$ spaces, Comput. Math. Appl. 56 (2008), no. 10, 2572-2579.

[9] R. Espinola and A. Fernandez-Leon, CAT(k)-spaces, weak convergence and fixed point, J. Math. Anal. Appl. 353 (2009), no. 1, 410-427.

[10] R. Espinola and W. A. Kirk, Fixed point theorems in $\mathbb{R}$-trees with applications to graph theory, Topology Appl. 153 (2007), no. 7, 1046-1055.

[11] H. Fukhar-ud-din and A. R. Khan, Convergence of implicit iterates with errors for mappings with unbounded domain in Banach spaces, Int. J. Math. Math. Sci. 10 (2005), 1643-1653.

[12] H. Fukhar-ud-din and A. R. Khan, Approximating common fixed points of asymptotically nonexpansive mappings in uniformly convex Banach spaces, Comput. Math. Appl. 53 (2007), no. 9, 1349-1360. 
[13] H. Fukhar-ud-din, A. R. Khan, D. O'Regan and R. P. Agarwal, An implicit iteration scheme with errors for a finite family of uniformly continuous mappings, Funct. Diff. Equns. 14 (2007), no. 2-4, 245-256.

[14] H. Fukhar-ud-din and S. H. Khan, Convergence of iterates with errors of asymptotically quasi-nonexpansive mappings and applications, J. Math. Anal. Appl. 328 (2007), no. 2, 821-829.

[15] H. Fukhar-ud-din, A. A. Domlo and A. R. Khan, Strong convergence of an implicit algorithm in $C A T(0)$ spaces, Fixed Point Theory and Applications, (2011), Article ID 173621, 11 pages.

[16] K. Goebel and S. Reich, Uniform convexity, hyperbolic geometry, and nonexpansive mappings, Vol. 83 of Monograph and Textbooks in Pure and Applied Mathematics, Marcel Dekker Inc., New York, NY, USA, 1984.

[17] W. Guo and Y. J. Cho, On the strong convergence of the implicit iterative process with errors for a finite family of asymptotically nonexpansive mappings, Appl. Math. Lett. 21 (2008), no. 10, 1046-1052.

[18] N. Hussain and M. A. Khamsi, On asymptotic pointwise contractions in metric spaces, Nonlinear Anal.: TMA, 71 (2009), no. 10, 4423-4429.

[19] S. Imnang and S. Suantai, Common fixed points of multi-step Noor iterations with errors for a finite family of generalized asymptotically quasi-nonexpansive mappings, Abstr. Appl. Anal. Vol. 2009, Article ID 728510, 14 pages.

[20] M. A. Khamsi and W. A. Kirk, An introduction to metric spaces and fixed point theory, Pure Appl. Math, Wiley-Interscience, New York, NY, USA, 2001.

[21] A. R. Khan, M. A. Khamsi and H. Fukhar-ud-din, Strong convergence of a general iteration scheme in CAT(0) spaces, Nonlinear Anal.: TMA, 74 (2011), no. 3, 783-791.

[22] A. R. Khan and M. A. Ahmed, Convergence of a general iterative scheme for a finite family of asymptotically quasi-nonexpansive mappings in a convex metric spaces and applications, Comput. Math. Appl. 59 (2010), no. 8, 2990-2995.

[23] A. R. Khan, A. A. Domlo and H. Fukhar-ud-din, Common fixed points of Noor iteration for a finite family of asymptotically quasi-nonexpansive mappings in Banach spaces, J. Math. Anal. Appl. 341 (2008), no. 1, 1-11.

[24] S. H. Khan and M. Abbas, Strong and $\triangle$-convergence of some iterative schemes in CAT(0) spaces, Comput. Math. Appl. 61 (2011), no. 1, 109-116.

[25] W. A. Kirk, Geodesic geometry and fixed point theory, in Seminar of Mathematical Analysis (Malaga/Seville, 2002/2003), Vol. 64 of Coleccion Abierta, 195-225, University of Seville Secretary of Publications, Seville, Spain, 2003.

[26] W. A. Kirk, Geodesic geometry and fixed point theory II, in International Conference on Fixed point Theory and Applications, 113-142, Yokohama Publishers, Yokohama, Japan, 2004.

[27] W. A. Kirk, Fixed point theory in CAT(0) spaces and $\mathbb{R}$-trees, Fixed Point Appl. 2004, no. 4, 309-316.

[28] W. A. Kirk, Some recent results in metric fixed point theory, J. Fixed Point Theory Appl. 2 (2007), no. 2, 195-207.

[29] W. Laowang and B. Panyanak, Strong and $\triangle$ convergence theorems for multivalued mappings in CAT(0) spaces, J. Inequal. Appl. Vol. 2009, Article ID 730132, 16 pages.

[30] L. Leustean, A quadratic rate of asymptotic regularity for CAT(0)-spaces, J. Math. Anal. Appl. 325 (2007), no. 1, 386-399.

[31] S. Saejung, Halpern's iteration in CAT(0) spaces, Fixed Point Theory Appl., Vol. 2010, Article ID 471781, 13 pages.

[32] C. Semple and M. Steel, Phylogenetics, Vol. 24 of Oxford Lecture Series in Mathematics and its Applications, Oxford University Press, Oxford, UK, 2003.

[33] N. Shahzad, Fixed point results for multimaps in CAT(0) spaces, Topology Appl. 156 (2009), no. 5, 997-1001. 
G. S. SALUJA

[34] Z. Sun, Strong convergence of an implicit iteration process for a finite family of asymptotically quasi-nonexpansive mappings, J. Math. Anal. Appl. 286 (2003), no. 1, 351-358.

[35] K. K. Tan and H. K. Xu, Approximating fixed points of nonexpansive mappings by the Ishikawa iteration process, J. Math. Anal. Appl. 178 (1993), 301-308.

[36] H. K. Xu and R. G. Ori, An implicit iteration process for nonexpansive mappings, Numer. Funct. Anal. Optim. Vol. 22 (2001), no. 5-6, 767-773.

G. S. SAluja

Department of Mathematics and Information Technology, Govt. Nagarjuna P.G. College of Science, Raipur-492010 (C.G.), India

E-mail address: saluja_1963@rediffmail.com, saluja1963@gmail.com 